\title{
Diurnal dynamics of water transport, storage and hydraulic conductivity in pine trees under seasonal drought
}

\author{
Tamir Klein ${ }^{(1-2)}$, \\ Shabtai Cohen ${ }^{(2)}$ \\ Indira Paudel (2-3), \\ Yakir Preisler ${ }^{(1-3)}$ \\ Eyal Rotenberg ${ }^{(1)}$, \\ Dan Yakir ${ }^{(1)}$
}

\begin{abstract}
The temporal dynamics of water transport and storage in plants have major implications for plant functioning and survival. In trees, stress on the conductive tissue can be moderated by water storage. Yet, trees can survive high percent loss of conductivity (PLC, up to $80 \%$ ), suggesting efficient recovery. We assess the role of tree water storage and PLC recovery based on simultaneous measurements of leaf transpiration, branch hydraulic conductivity, and stem sap-flow from different seasons in three study years in mature Pinus halepensis (Miller) trees in a semi-arid forest. During the wet season the rates of transpiration (T) and sap flow (SF) peaked at high morning and through the midday. During the dry season T peaked at $\sim 9: 00$ and then decreased, whereas SF lagged $\mathrm{T}$ and fully compensated for it only in the evening, resulting in a midday water deficit of $\sim 5 \mathrm{~kg}^{\mathrm{tree}}{ }^{-1}$, and with up to $33 \%$ of daily $\mathrm{T}$ derived from storage. PLC of $30-40 \%$ developed during mid-day and subsequently recovered to near zero within 2-3 hr in the dry season (May, June, and September), but not in the wet season (January). The observed temporal decoupling between leaf water loss and soil water recharge is consistent with optimization of the trees' water and gas exchange economy, while apparently facilitating their survival in the semi-arid conditions.
\end{abstract}

Keywords: Cavitation Reversal, Sap Flow, Semi-arid, Water Deficit, Xylem Embolism. angiosperms for which $50 \%$ PLC can be lethal (Choat et al. 2012, Meinzer \& McCulloh 2013). Field measurements in P. halepensis under semi-arid conditions (Maseyk et al. 2008) showed leaf water potential, $\Psi_{1}$ $<-2.5 \mathrm{MPa}$ throughout the day during the entire dry season, approaching the points of stomatal closure $\left(\Psi_{1}=-2.8 \mathrm{MPa}\right)$ and PLC50 $\left(\Psi_{1}=-3.9 \mathrm{MPa}\right)$. Carbon uptake continues throughout the dry season, in spite of the harsh conditions, mainly to support fresh needle growth (Maseyk et al. 2008). This "risky" behavior of $P$. halepensis was contrasted by relatively high survival, growth and productivity in a semi-arid forest site (Grünzweig et al. 2007, Maseyk et al. 2008, Klein et al. 2014b). Together, these observations suggest that the xylem
(1) Department of Earth and Planetary Sciences, Weizmann Institute of Science, Rehovot 76100 (Israel); (2) Institute of Soil, Water and Environmental Sciences, ARO Volcani Center, Beit Dagan 50250 (Israel); (3) Robert H. Smith Institute of Plant Sciences and Genetics in Agriculture, Faculty of Agricultural, Food and Environmental Quality Sciences, the Hebrew University of Jerusalem, Rehovot (Israel)

@ Tamir Klein (tamirkl@volcani.agri.gov.il)

Received: Mar 08, 2016 - Accepted: Jul 19, 2016

Citation: Klein T, Cohen S, Paudel I, Preisler Y, Rotenberg E, Yakir D (2016). Diurnal dynamics of water transport, storage and hydraulic conductivity in pine trees under seasonal drought. iForest 9: 710-719. - doi: 10.3832/ifor2046-009 [online 2016-08-21]

Communicated by: Silvano Fares of $P$. halepensis regularly experiences high cavitation levels during the dry season and that this species must have some immunity to the effects of cavitation, allowing its survival and continuous activity under drought.

Isohydric-like, low wood density species such as $P$. halepensis are expected to have a relatively high capacity to store water (Meinzer et al. 2009) and possibly also to refill cavitated xylem (as shown for angiosperm species - Taneda \& Sperry 2008). Some level of water storage is common in tree stems and is active in the daily water balance, which results in temporal decoupling of sap flow $(S F)$ from transpiration (T). A short ( $0.5 \mathrm{hr}) T$ vs. $S F$ lag is usually expected due to changes in $\Psi_{1}$, e.g., the release of water from leaves in early morning, when $\Psi_{1}$ decreases from its pre-dawn value to an operational value. A $T$ vs. $S F$ lag was discussed (Cruiziat et al. 2002) but not frequently tested, presumably due to the differentiation between studies using gas $(T)$ and liquid phase $(S F)$ measurement techniques. Two notable exceptions are Zweifel et al. (2001) and Fisher et al. (2007), who showed time lags between $T$ and $S F$ of 0.5-3 hr. Comparing $S F$ rates at the bottom and high crown of large tropical trees, Meinzer et al. (2003) found up to a $2 \mathrm{hr} \mathrm{lag}$ time. The role of tree water storage was shown in many studies (Zweifel et al. 2001, Meinzer et al. 2003, McLaughlin et al. 2003, Fisher et al. 2007, Meinzer et al. 2009), some showing a major storage contribu- 
tion, e.g., $10-75 \%$ of daily $T$ in potted, young Norway spruce (Picea abies - Zweifel et al. 2001), or a more minor contribution of 2 $10 \%$ in adult yellow poplar (Lirodendron tulipifera - McLaughlin et al. 2003) and down to zero stem storage in the woody monocot Bamboo suffering from cavitation (Yang et al. 2012).

Sap flow is usually under large negative pressures and subsequently trees live under the threat of cavitation (Tyree \& Sperry 1988). Cavitation breaks the continuity of water columns and hence the water supply to transpiring leaves. Xylem embolism and cavitation reduce hydraulic conductance and therefore bear major implications for plant function and survival. Cavitation can be fatal to trees (Tyree \& Sperry 1988, Brodribb \& Cochard 2009, Klein et al. 2011) and irreversible (Tyree \& Sperry 1988). Among P. halepensis provenances, those with higher sensitivity to cavitation generally had higher mortality rates in the field (Klein et al. 2012). Since water is transported in the xylem under constant tension (i.e., water potential $-\Psi<$ o) the possibility of refilling was initially ruled out. However, empirical evidence for the reversibility of cavitation became available from experimental data on induced and native embolism (Tyree et al. 1999). A proposed refilling mechanism overcame the tension enigma by segregation, i.e., the refilling process is preceded by isolation of the cavitated section from the water conducting system (Holbrook \& Zwieniecki 1999). Cavitation repair is usually allowed once trees are re-watered (Ogasa et al. 2013), e.g., between hot day and cooler night (Trifilò et al. 2014).

Cavitation removal was shown in grapevine (Vitis vinifera - Zufferey et al. 2011) where synchrotron $\mathrm{x}$-ray microtomography (microCT) facilitated visualization of the refilling process, confirming the segregation hypothesis and showing water influx from surrounding living cells (Brodersen et al. 2010). The new microCT technology per- mits direct, nearly non-invasive embolism measurement. Yet in mature trees in the field, hydraulic conductivity measurements still offer the best way to detect changing levels of embolism.

The refilling process could result from osmotic gradients generated by sucrose in walls of embolized vessels (Secchi \& Zwieniecki 2011). In the desert woody shrub Encelia farinosa, embolism repair occurs at night while stomata are open and transpiring, without the need to isolate the cavitated section (Espino \& Schenk 2011). In Bamboo (Sinarundinaria nitida) nocturnal root pressure was sufficient to cause recovery from embolism in the leaves (Yang et al. 2012). In conifers, mechanisms of embolism repair are currently unclear and might differ from those proposed for angiosperms due to differences in xylem structure and chemical composition, but embolism repair has been demonstrated in at least eight conifer species (McCulloh et al. 2011, Brodersen et al. 2010 and references therein), although microCT showed no refilling in Sequoia sempervirens saplings (Choat et al. 2014). Additionally, some of the measurements involving the cutting of xylem under tension might have overestimated the levels of embolism and recovery (Wheeler et al. 2013) and hence must be taken with caution. In $P$. halepensis under drought, embolism repair was detected using acoustic emissions, a nonquantitative method (Borghetti et al. 1991, 1998).

We hypothesize that water storage and maintenance of hydraulic conductivity must be integral components of the water management in $P$. halepensis to sustain activity and survival under continuous dry conditions of the summer. To test this hypothesis we applied a high temporal resolution sampling strategy to study in vivo the dynamics of hydraulic conductivity in mature $P$. halepensis trees in a semi-arid forest, where extreme seasonal drought is the norm.

\section{Materials and methods}

\section{Site description and environmental conditions}

Our study was conducted in the Yatir forest, a 45-yr-old P. halepensis plantation located at the northern edge of the Negev desert, Israel $\left(31^{\circ} 20^{\prime} \mathrm{N}, 35^{\circ} 20^{\prime} \mathrm{E}\right)$. The forest covers an area of 2800 ha and lies on a predominantly light brown Rendzina soil (79 $\pm 45.7 \mathrm{~cm}$ deep), overlying chalk and limestone bedrock. The climate is hot (40yr average mean annual temperature is 18 ${ }^{\circ} \mathrm{C}$ ) and dry (40-yr average mean annual precipitation is $285 \pm 88 \mathrm{~mm}$ ). Rainfall is restricted to the wet season between November/December and April/May, increasing soil water content from $12-15$ to $32-33 \% \mathrm{v} / \mathrm{v}$ (Fig. 1). Mean daily vapor pressure deficit is mostly below $1.0 \mathrm{kPa}$ during the wet season, and well over 2.0 and up to $5.0 \mathrm{kPa}$ during the long dry season. Stand density is ca. 300 trees $\mathrm{ha}^{-1}$, leading to an average leaf area index of about 1.50 .

\section{Study trees}

In 2000, an instrumented flux tower was installed in the geographic center of the forest. Across the forest, trees were planted around the same time and at homogeneous density, and hence the tower stand can be considered as a representative stand. In 2009, sap flow probes were installed on sixteen trees ca. $70 \mathrm{~m}$ from the tower, defined as the observation plot within the tower stand. A subset of 1-4 trees of these sixteen trees was selected for all other measurements and samples taken between 2009 and 2014 (hydraulic conductivity, needle gas exchange, water potential, and relative water content). These four trees had the longest and most stable sap flow record in the observation plot, and were arbitrarily selected as typical representative healthy trees; other trees in the same stand died following the drought years of 2008, 2009, and 2011 (Klein et al. 2014b), or showed some level

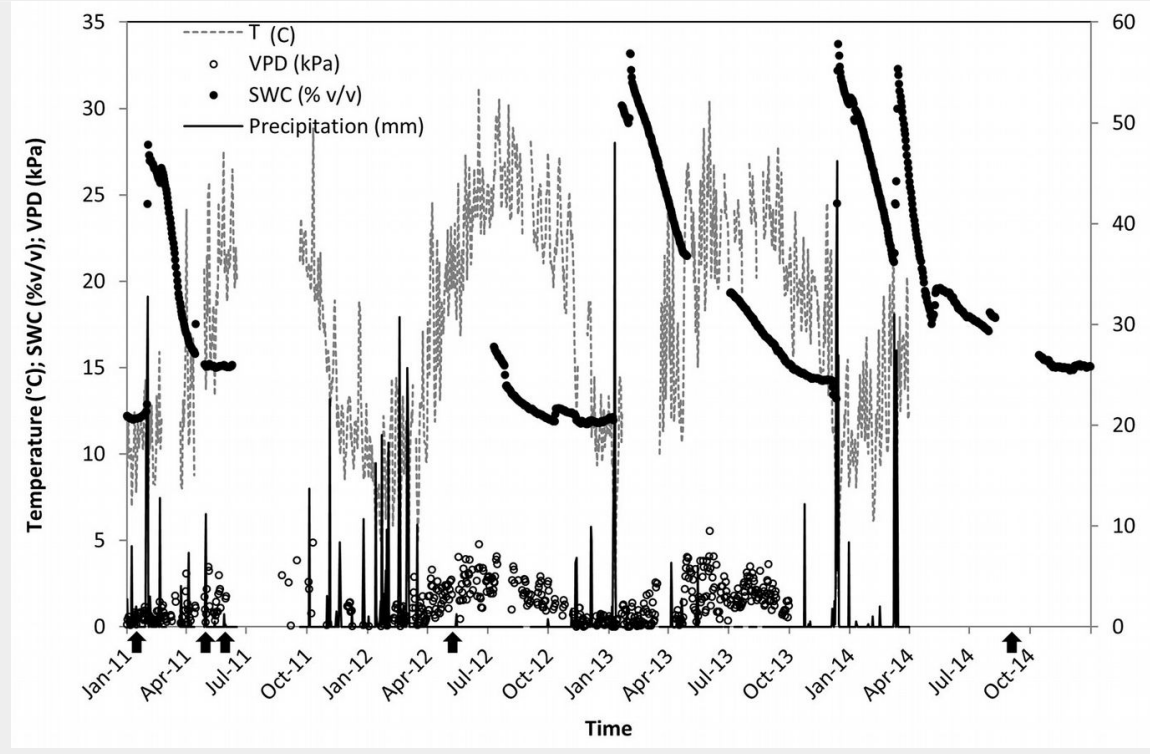

Fig. 1 - Site environmental conditions in 2011-2014. Daily precipitation (P); mean soil water content at $30 \mathrm{~cm}$ below surface (SWC); mean vapor pressure deficit (VPD); and mean air temperature over the forest canopy $(T)$. Data are missing due to technical impediments for $T$ and VPD during June-September 2011 and in 2014; for SWC during June 2011-July 2012; but not for P. Black arrows in the bottom indicate major field day campaigns. 
of drought stress (Klein et al. 2014a). The forest inventory performed in 2010 in the tower stand showed that tree height and diameter at breast height (DBH) were 10.2 $\pm 0.2 \mathrm{~m}$ (mean $\pm \mathrm{SE}$ ) and $19.8 \pm 0.4 \mathrm{~cm}$, respectively $(n=177)$. In the observation plot, tree height and DBH were $9.5 \pm 0.3 \mathrm{~m}$ and $18.2 \pm 0.9 \mathrm{~cm}$, respectively $(n=16)$. Among the subset of trees selected for intensive measurements, tree height and DBH were $9.0 \pm 0.6 \mathrm{~m}$ and $21.5 \pm 1.3 \mathrm{~cm}$, respectively $(n=4)$. Therefore, the four selected trees had, on average, slightly higher DBH than their plot neighbors, but not significantly higher than the stand-level mean. Considering the relatively low stand density and LAI in Yatir forest, lower tree crowns are sunlit and active, facilitating measurements at 1.3-2.0 $\mathrm{m}$ aboveground.

\section{Xylem hydraulic conductivity}

Branch sections $(\sim 5 \mathrm{~mm}$ diameter, $\sim 30 \mathrm{~cm}$ length) were sampled from lower crowns (1.3-2.0 m) of 1-4 P. halepensis trees every 1$2 \mathrm{hr}$ during five field days between January 2011 and September 2014. In P. halepensis in Yatir forest, the outer $4 \mathrm{~cm}$ of the sapwood is conductive (Cohen et al. 2008), which, according to tree-ring counting, was formed within $27 \pm 1$ years. The $5 \mathrm{~mm}$ diameter branches whose conductivity was measured were $13 \pm 1$ years old and hence fully conductive. All measurements were done according to the best practices at the time of measurement, which changed during the time-frame of this study, and we adapted accordingly. Therefore, the protocol used in 2011-2012 was replaced by an improved protocol in 2014, following the validations made by Delzon et al. (2010) and by Wheeler et al. (2013), which are detailed below. However, the results from the different protocols remained consistent.

In the first protocol, specific hydraulic conductivity $\left(K_{\mathrm{s}}\right)$ was measured in the lab, under low pressure (0.02 $\mathrm{MPa}$ ) before and after perfusing the xylem tissue at a high pressure of $0.5 \mathrm{MPa}$. The branch section was cut in the field and resin secretion from the cuts was eliminated by placing both ends ( $5 \mathrm{~cm}$ from cut tips) in a water bath at $95^{\circ} \mathrm{C}$ for $10 \mathrm{~min}$ (adapted from Waring \& Silvester 1994). The resin treatment was essential (Melcher et al. 2012) and also helped remove trapped gas from branch ends, which could otherwise create artifacts (Wheeler et al. 2013). Experimenting with branches of well-watered Olea europaea showed that the effect of this treatment on $K_{\mathrm{s}}$ was $<5 \%$. Next, stem sections were submerged in distilled water and transferred to the lab. In the lab, the upstream end of each branch was then fitted with a rubber gasket, while still submerged, to a latex pipe fed by a degassed $10 \mathrm{mM} \mathrm{KCl}$ solution reservoir. A hydrostatic pressure of $0.02 \mathrm{MPa}$ was applied by placing the reservoir exactly $2 \mathrm{~m}$ above the stem section. For two hr, water dripping from the distal end of the branch section was collected and weighed every $20 \mathrm{~min}$. The flow rate was steady, producing a linear increase in the efflux water mass ( $r^{2}$ of linear fits > 0.9) and indicating no rehydration of the branch. To test the effect of hydrostatic pressure on $K_{\mathrm{s}}$, nine branches were exposed to hydrostatic pressures of $0.0015-0.0070 \mathrm{MPa}$. $K_{\mathrm{s}}$ increased from practically zero to $0.4 \mathrm{~kg} \mathrm{~m}^{-1} \mathrm{MPa}^{-1} \mathrm{~s}^{-1}$ at pressure larger than $0.003 \mathrm{MPa}$ (Fig. S1 in Supplementary material). The water flow rate $\left(\mathrm{kg} \mathrm{s}^{-1}\right)$ was divided by the pressure gradient $(0.02 \mathrm{MPa})$ along the $\sim 30 \mathrm{~cm}$ stem length to provide the hydraulic conductivity $K_{\mathrm{h}}\left(\mathrm{kg} \mathrm{m} \mathrm{MPa}{ }^{-1} \mathrm{~s}^{-1}\right)$, as described by Tyree \& Alexander (1993). $K_{\mathrm{h}}$ was further divided by the xylem cross-sectional area to get specific hydraulic conductivity, $K_{\mathrm{s}}\left(\mathrm{kg} \mathrm{m}^{-1}\right.$ $\left.\mathrm{MPa}^{-1} \mathrm{~s}^{-1}\right)$. Branch sections were then fitted with high-pressure valve to a high-pressure pipe fed by $10 \mathrm{mM} \mathrm{KCl}$ solution reservoir placed inside a Scholander pressure chamber. The segment was perfused at $0.5 \mathrm{MPa}$ for $5 \mathrm{~min}$ and then a second measurement of $K_{\mathrm{s}}$ was made to get the maximum specific conductivity, $K_{\mathrm{s} \max }$. Measurements of $K_{\mathrm{s}}$ and $K_{\mathrm{s} \max }$ were further used to identify loss of conductivity, which can be attributed to xylem cavitation according to (eqn. 1):

$$
P L C=100 \cdot \frac{\left(K_{s \max }-K_{s}\right)}{K_{s \max }}
$$

where $P L C$ is the percent loss of conductivity (\%) due to cavitation.

In the second protocol, resin secretion was stopped by immediate immersion in ice water. Branch sections were re-cut under degassed water in the lab to a length of $10 \mathrm{~cm}$, to avoid potential artifacts related to induced cavitation due to cutting in the field (Wheeler et al. 2013). $K_{\mathrm{s}}$ was measured in a similar fashion but using a lower hydrostatic pressure of $0.007 \mathrm{MPa}$ by placing a degassed $10 \mathrm{mM} \mathrm{KCl}$ solution reservoir $0.7 \mathrm{~m}$ above the stem section. Branches were not exposed to higher pressure, to avoid sealing of the torus-margo pit membrane (Delzon et al. 2010). For the perfusion treatment, degassed water was drawn through the stem overnight by putting the stem in a beaker of degassed water and connecting the other side to a vacuum line whose negative pressure was $\sim 0.07 \mathrm{MPa}$. Observation of the water level in the beaker showed that a substantial amount of water had perfused the stem overnight. A second measurement at 0.007 MPa provided the reference conductivity, $K_{\text {smax. }}$

\section{Sap flow}

Sap flow $(S F)$ was measured continuously since September 2009 on sixteen trees in Yatir forest using lab manufactured thermal dissipation sensors (Granier \& Loustau 1994) calibrated by comparison with commercial heat balance sensors (EMS, Brno, (zech Republic) in the same trees. All probes were installed at $1.3 \mathrm{~m}$ above the ground and $2 \mathrm{~cm}$ into the sapwood. Mea- surements were taken every $30 \mathrm{~s}$ and the $30 \mathrm{~min}$ average value was saved on a CR1000 ${ }^{\oplus}$ data-logger (Campbell Scientific Inc., Utah, USA) and transmitted via internet to the lab at the Weizmann Institute of Science. Sap flow rates $\left(\mathrm{kg} \mathrm{hr}^{-1}\right)$ were calculated in relation to the minimum sap flux during the $24 \mathrm{hr}$ period (typically at night), as shown in the empirical equation (eqn. 2) of Granier \& Loustau (1994), modified by Kanety et al. (2014):

$$
S F=L C F \cdot C F \cdot 0.04284 \cdot\left[\frac{\Delta T_{\max }-\Delta T_{r}}{\Delta T_{r}}\right]^{1.231}
$$

where $S F$ is the half hourly sap flow rate; $L C F$ is the correction factor for the $2 \mathrm{~cm}$ probes considering the radial distribution of sap velocity (for P. halepensis in Yatir Cohen et al. 2008) and calculated specifically for individual trees (Paudel et al. 2013, Kanety et al. 2014); $C F$ is a calibration factor of 2.5 (Steppe et al. 2010, Paudel et al. 2013, Kanety et al. 2014), validated here by comparison with the heat balance sensors; $\Delta T_{\mathrm{r}}$ is the average half hourly temperature difference between heated and nonheated probes, and $\Delta T_{\max }$ the maximum temperature difference measured during the $24 \mathrm{hr}$ period (assumed to be at a negligible sap flow rate, typically at night).

\section{Stem diameter variations}

Delicate changes in stem diameter (down to $\pm 1 \mu \mathrm{m}$ ) were recorded continuously since September 2009 with high-resolution band dendrometer (EMS, Brno, Czech Republic) fitted at $1.9 \mathrm{~m}$ around one of the four $P$. halepensis trees used for intensive measurements. To detect diurnal variations, output data were set to zero at midnight of each $24 \mathrm{hr}$ period. Stem diameter variations make a good proxy for tree water relations (Zweifel et al. 2001) because they reflect changes in the elastic tissues of the stem (i.e., phloem and bark), which have hydraulic connections to the xylem. The negative pressure associated with water transport in the xylem withdraws water from these elastic tissues, thereby decreasing stem diameter. This shrinkage stops as soon as the tension is relaxed, and stem diameter increases again.

\section{Leaf gas exchange, water potential and} relative water content

Leaf photosynthesis $(A)$, transpiration $(T)$ and stomatal conductance $\left(g_{\mathrm{s}}\right)$ were measured using a LiCor $6400^{\oplus}$ photosynthesis system (Licor Inc., Lincoln, NE, USA) on the four trees every 30-60 min during five field days between April 2010 and June 2011. These were the trees used for hydraulic conductivity and sap flow measurements. Lower crown (1.3-2.0 m) cohorts of sunlit, 1-year old needles were marked for repeated measurement. Leaf chamber conditions were adjusted to ambient and all gas exchange parameters were expressed on a projected needle area basis of $3 \mathrm{~cm}^{2}$ based on the uniform area of twelve adjacent 


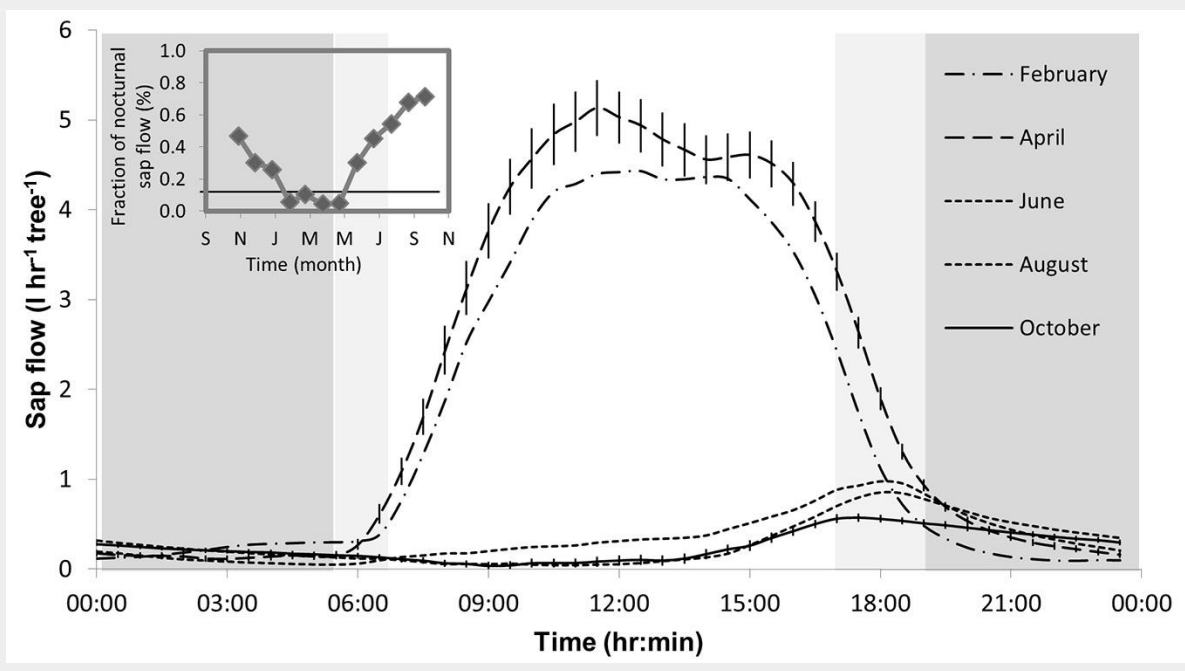

Fig. 2 - Diurnal changes in the monthly average sap flow $(S F)$ rate in Pinus halepensis in the Yatir forest, with the fraction of nocturnal sap flow shown in the inset (horizontal line represents the annual average, 0.16). Nighttime is indicated by a light or dark background, depending on the date. Error bars, shown for April and June for ease of reading, represent the standard error of the mean ( $n=16$ trees $\times 28-31$ days), and are not observed when smaller than symbols.

needles (Maseyk et al. 2008). Measurements were upscaled to tree-scale transpiration by multiplying by leaf area (Grünzweig et al. 2007), since for the low LAI (1.5) it is fair to assume that all leaves can be considered as sunlit and equally active. Leaf water potential $\left(\Psi_{1}\right)$ was measured using the pressure chamber technique. Small (5-7 cm long) twigs were cut from the same trees used for the gas exchange measurements at similar height and side and put in a pressure chamber (Arimad $2^{\circledR}$, A.R.I, Kfar Charuv, Israel) fed by a Nitrogen gas cylinder and equipped with a lamp-carrying magnifying glass. Gas pressure within the chamber was gradually increased $(\sim 1$ MPa $\min ^{-1}$ ) until water emerged from the protruding cut branch surface, and the pressure value was recorded as leaf water potential $\left(\Psi_{1}\right)$. Due to staff and equipment limitations, $\Psi_{1}$ was only measured during a few field days. Needle relative water content (nRWC) was determined from three subsequent measurements: fresh leaf mass (in situ), water-saturated mass by immersion, and oven-dry mass (in the lab). Consecutive weightings verified complete saturation and drying until stable mass was achieved.

Tab. 1 - Diurnal maxima of leaf transpiration $\left[t_{\max }(T)\right]$ and sap flow $\left[t_{\max }(S F)\right]$ along the year in the Yatir forest and the time difference between them [Lag time: $t_{\max }(S F)$ $\left.t_{\max }(T)(\mathrm{hr})\right]$.

\begin{tabular}{cccc}
\hline Date & $\boldsymbol{t}_{\max }(\boldsymbol{T})$ & $\boldsymbol{t}_{\max }(\boldsymbol{S} \boldsymbol{F})$ & Lag time \\
\hline 1-Oct & $11: 00$ & $19: 00$ & 8.0 \\
1-Nov & $10: 30$ & $16: 30$ & 6.0 \\
1-Dec & $10: 00$ & $12: 30$ & 2.5 \\
1-Jan & $09: 00$ & $14: 30$ & 5.5 \\
1-Feb & $09: 30$ & $13: 30$ & 4.0 \\
1-Mar & $09: 30$ & $14: 00$ & 4.5 \\
1-Apr & $09: 30$ & $10: 00$ & 0.5 \\
1-May & $09: 30$ & $13: 00$ & 3.5 \\
1-Jun & $09: 30$ & $18: 30$ & 9.0 \\
1-Jul & $09: 00$ & $18: 30$ & 9.5 \\
1-Aug & $09: 00$ & $18: 00$ & 9.0 \\
1-Sep & $09: 30$ & $18: 00$ & 8.5 \\
\hline
\end{tabular}

April $96 \%$ of $S F$ occurred during the daytime, during September-October as much as $70 \%$ of $S F$ occurred at night (Fig. 2 inset). The dynamics of leaf scale transpiration did not reflect the major changes in $S F$. $T$ was always restricted to daytime throughout the year, and its peak, $t_{\max }(T)$, was in the morning in all seasons (Tab. 1), and moved from mid-day in the wet season to midmorning ( 9:00) in the dry season. Consequently, the lag time between $t_{\max }(T)$ and the less distinct $t_{\max }(S F)$ increased from 30 min in April up to a maximum of $9.5 \mathrm{hr}$ in July (Tab. 1).

\section{Daily and seasonal dynamics of hydraulic conductivity}

The daily course of $P L C$, often used as an indicator of xylem cavitation, showed a major shift from consistent zero $P L C$ in the wet season (January) to highly fluctuating, increasing up to $50 \%$ in the dry season (Fig. 3). In the dry season PLC peaked two times during the day: first in the morning and later again in the afternoon. In between, $P L C$ declined to $0-5 \%$ and xylem conductivity was fully restored. Morning and afternoon $P L C$ peaked in 1-3 hr and consequently was reversed over a similar time period. The standard error among branches of the same tree was $7.4 \%$ on average, and $16.4 \%$ among branches of multiple trees in 2012. Such variations are expected from a highly dynamic process that may not occur uniformly throughout the entire xylem and among multiple trees. Nevertheless, using the improved protocol in 2014 the standard errors decreased to $2.2 \%$ on average while showing a similar pattern (i.e., there was still consistency between the old and newer methodologies, which add robustness to the results). In May 2011 and September 2014 differences in PLC in different times of the day were significant, e.g., between 10:40 and 11:40 in May 2011, and between 8:00 and 8:30 in September 2014. The exact timing of the $P L C$ highs and lows changed between observation days, between the beginning of the dry season (May) and its end (Sep- 
Fig. 3 - Percent loss of conductivity, PLC (a measure of xylem cavitation) in Pinus halepensis branches sampled in the Yatir forest in 2011, 2012, and 2014 (upper, middle, and bottom panels, respectively). Changes in vapor pressure deficit $(V P D)$ are indicated by dashed lines. $P L C$ values are means from three branches of one tree (2011) or from three-four different trees (2012, 2014); PLC was determined using the first protocol in 2011 and 2012 (see Methods) or the second protocol in 2014. Different letters indicate significant differences among sampling times, with $P$-values indicated at upper right corners. Error bars represent the standard error of the mean.

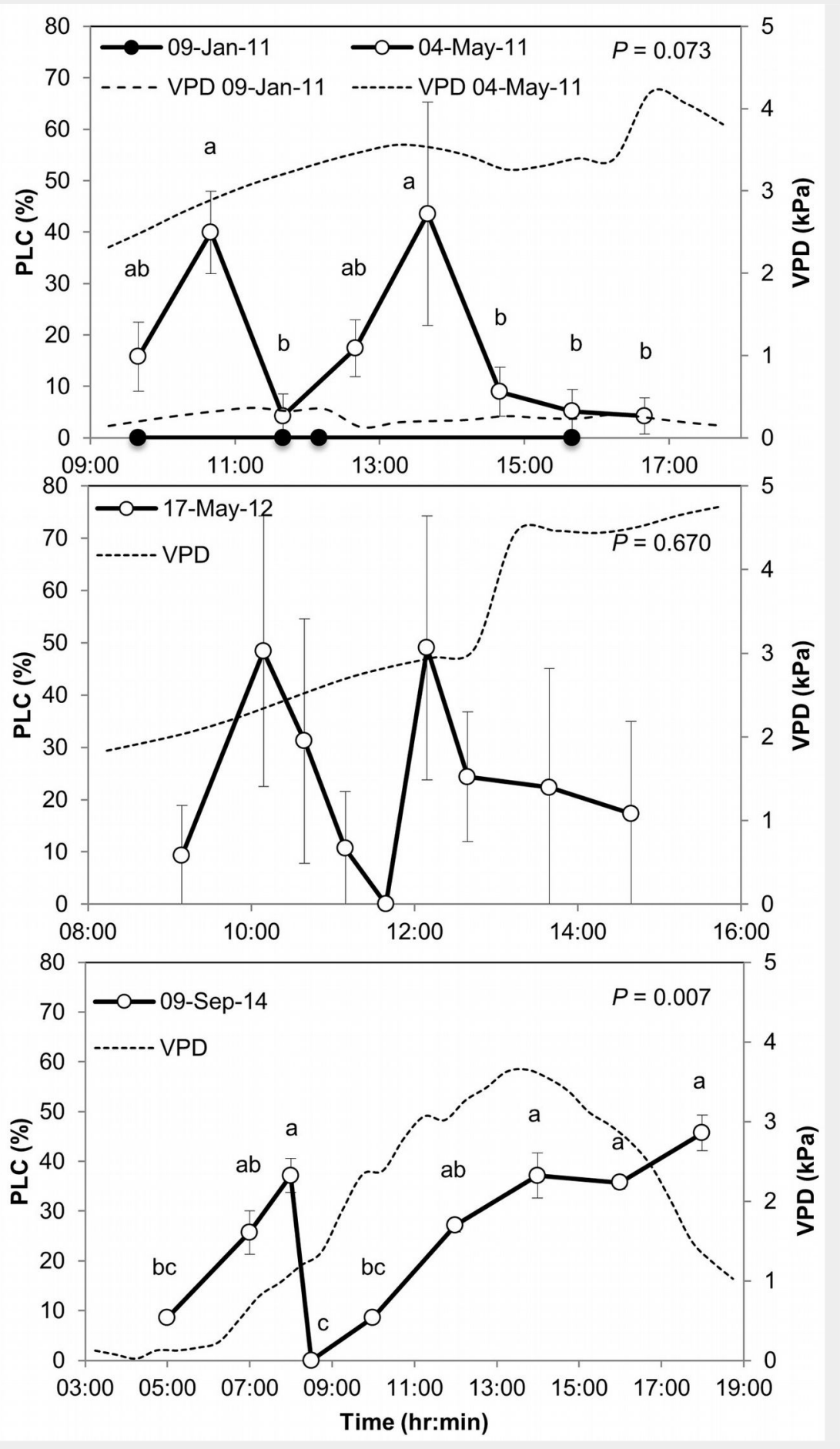

tember), consistent with previously observed seasonal shift in the peak of the daily activity cycle at the site (Maseyk et al. 2008). Xylem conductivity partially recovered in the afternoon of May 2011 and 2012, but not in September 2014. The lower vapor pressure deficit (VPD) in September vs. May meant that stomatal gas exchange was maintained throughout the afternoon hours in September despite low soil water availability, in turn inhibiting reversal of cavitation during the day.

The dynamics of branch hydraulic conductivity $\left(K_{\mathrm{s}}\right)$ and water potential $\left(\Psi_{1}\right)$ in neighboring trees were further examined. At predawn of the September 2014 field day trees had various levels of $K_{\mathrm{s}}$ and a uniform $\Psi_{1}$ of $-2.25 \mathrm{MPa}$ (Fig. 4). During the next 5 hours $K_{\mathrm{s}}$ reached its minimum and subsequently, maximum values, while $\Psi_{1}$ decreased monotonously by 1.0 MPa. During the rest of the day and until sunset, $K_{\mathrm{s}}$ continued to decline gradually, while $\Psi_{1}$ remained around $-3.15 \mathrm{MPa}$, a level associated with 33\% PLC (Fig. S2 in Supplementary material).

\section{Contemporary changes in tree}

hydraulics and gas exchange

More detailed 24-hr gas exchange and hydraulic measurements in both the wet and dry periods were used to help understand the dynamics of the interactions reported above. In the wet season, photosynthetically active radiation $(P A R)$ was between 200 and $900 \mu \mathrm{mol} \mathrm{m}^{-2} \mathrm{~s}^{-1}$ during most of the light hours (8:15-15:15), and $V P D$ was low (Fig. 5A-B). Under these favorable conditions, net carbon assimilation $(A)$ reached $17 \mu \mathrm{mol} \mathrm{m} \mathrm{m}^{-2}$ at noontime and stomatal conductance $\left(g_{\mathrm{s}}\right)$ was $>0.1 \mathrm{~mol} \mathrm{~m}^{-2} \mathrm{~s}^{-1}$ throughout the entire day. Water transport rates in the xylem $(S F)$ and from the leaf (transpiration, $T$ ) were relatively synchronized (Fig. 5C) and the short lag could be explained by the effect of changes in $\Psi_{1}$ (see Introduction). Stem diameter decreased by $40 \mu \mathrm{m}$ between 8:15 and 12:15, 


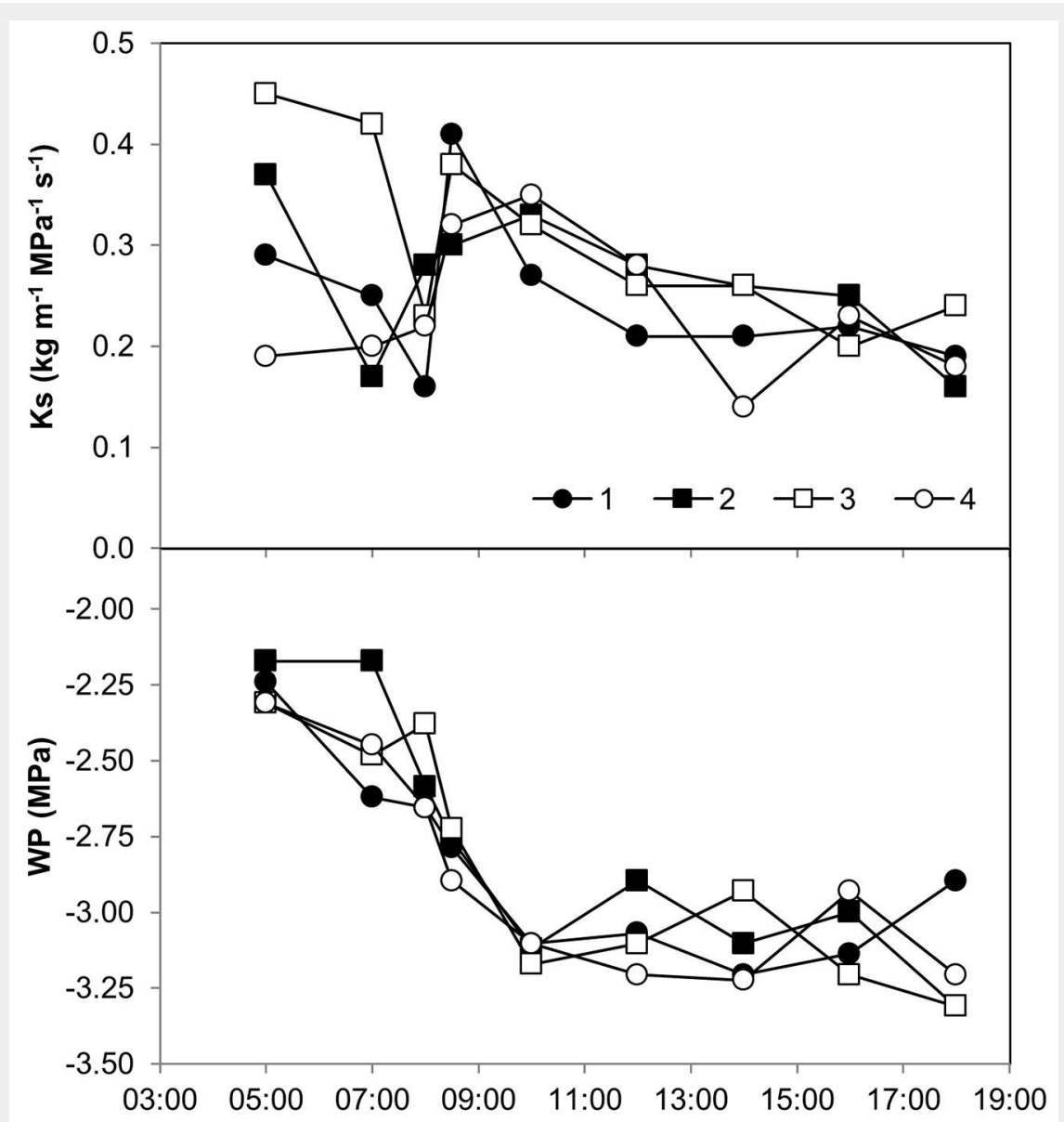

Time (hr:min)

Fig. 4 - Diurnal changes in xylem specific hydraulic conductivity $\left(K_{\mathrm{s}}\right)$ and shoot water potential $(W P)$ in four neighboring Pinus halepensis trees in the Yatir forest during 9 Sep 2014.

when $S F$ was increasing, or at its peak of $4.5 \mathrm{~kg} \mathrm{hr}^{-1}$ (Fig. 5C-D). No cavitation was observed at any of the four sampling times during the day.

Under the regular dry season drought, net assimilation $A$ was observed in the light hours but was not synchronized with PAR (Fig. 5E), probably due to the development of high $V P D$ around midday $(>3 \mathrm{kPa}$ - Fig. $5 \mathrm{~F}$; see also Maseyk et al. 2008) The increased $V P D$ resulted in reduced $g_{s}$ from $\sim 0.05 \mathrm{~mol} \mathrm{~m}^{-2} \mathrm{~s}^{-1}$ at 7:45 to below $0.01 \mathrm{~mol}$ $\mathrm{m}^{-2} \mathrm{~s}^{-1}$ at 12:15 (Fig. 5F). In the afternoon, around 16:00, VPD decreased below $3 \mathrm{kPa}$ and $\mathrm{g}_{\mathrm{s}}$ increased two folds to $\sim 0.02 \mathrm{~mol} \mathrm{~m}^{-2}$ $\mathrm{s}^{-1}$, still lower than the morning peak, presumably due to the low light levels approaching sunset (when $P A R=50 \mu \mathrm{mol} \mathrm{m}{ }^{-2}$ $\mathrm{s}^{-1}$ by $\left.17: 45\right)$. Consistent with this pattern, the diurnal curve of $A$ also showed a morning peak $\left(3 \mu \mathrm{mol} \mathrm{m} \mathrm{m}^{-2} \mathrm{~s}^{-1}\right)$ followed by a midday depression and a smaller afternoon peak ( $1 \mu \mathrm{mol} \mathrm{m} \mathrm{m}^{-2} \mathrm{~s}^{-1}$, Fig. $\left.5 \mathrm{E}\right)$. In contrast to $A$, the observed diurnal changes in $T$ reflected the combined effects of $g_{s}$ and $V P D$, where variations in $T$ can be approximated by variations in $g_{\mathrm{s}} \times V P D$. Therefore $T$ peaked at $0.73 \mathrm{mmol} \mathrm{m}^{-2} \mathrm{~s}^{-1}$ at 9:15 and declined to $0.15 \mathrm{mmol} \mathrm{m}^{-2} \mathrm{~s}^{-1}$ at 13:45 (Fig.
5G). Between 14:00 and 18:30 $T$ stabilized at around $0.25 \mathrm{mmol} \mathrm{m}^{-2} \mathrm{~s}^{-1}$, reflecting the inverse relationship between $g_{s}$ and $V P D$. Comparing the dynamics in $T$ and $S F$ (Fig. 5G) indicated that: (1) $T$ had large fluctuations, while changes in $S F$ were more gradual; and (2) $T$ ceased at night whereas $S F$ continued long after sunset. Stem shrinkage of $30 \mu \mathrm{m}$ matched the time-frame between the start of $S F$ increase (8:15) and decrease (18:45), reflecting the longer $S F$ time-window in dry vs. wet season. But unlike the constant shrinkage rate of $10 \mu \mathrm{m}$ $\mathrm{hr}^{-1}$ in January, the dry season shrinkage rate changed from $3 \mu \mathrm{m} \mathrm{hr}^{-1}$ (8:15-10:15) to a moderate $1 \mu \mathrm{m} \mathrm{hr}^{-1}(10: 15-15: 15)$ and then to $6 \mu \mathrm{m} \mathrm{hr}^{-1}$ (15:15-18:45). Stem contraction during the dry season day did not reach negative values due to higher relaxation at night. Fluctuations in xylem conductivity dynamics were associated with the decoupling between $T$ and $S F$, reflected by rapid changes in the PLC (Fig. $5 \mathrm{H}$ ), with two transient peaks of $30 \%$ and $40 \%$ at 9:45 and 17:45, respectively. The $P L C$ dynamics on 6 June 2011 were generally similar to those observed in May 2011 and 2012 (Fig. 3), albeit conductivity did not fully recover in the evening. PLC and transient decreases in needle relative water content ( $n R W C$, from 77 to $63 \%$ - data not shown) occurred simultaneously with high $g_{s}$, while the recovery in $P L C$ and $n R W C$ was at decreasing $g_{\mathrm{s}}$, which may indicate that $P L C$ reversal was dependent on reduced rates of water loss and increasing $n R W C$.

Seasonal changes were observed in the $T$ vs. $S F$ dynamics, between wet and dry season (Fig. $5 \mathrm{C}$ and Fig. $5 \mathrm{C}$, respectively). The increase in $T$ from 6:00 to 9:00 occurred in both seasons, but the $S F$ supply of water for $T$ was substantially delayed in the dry season. Upscaling leaf-scale transpiration measurements ( $\left.\mathrm{mmol} \mathrm{m}^{-2} \mathrm{~s}^{-1}\right)$ to tree-scale transpiration $\left(\mathrm{kg} \mathrm{hr}^{-1}\right)$, using individual tree leaf area estimates based on our own sitespecific allometric equations (Grünzweig et al. 2007), showed that large (3-5 kg) water deficits developed in the tree during the day, but the trees also re-hydrated daily, i.e., tree water content did not decline during the season. Integrating the dry season diurnal water use of an average tree in Yatir forest yields a value of $15 \mathrm{~kg} \mathrm{day}^{-1}$. This implies that during the light hours of a typical dry season day $20-33 \%$ of the transpiration came from water storage.

\section{Discussion}

Temporal decoupling between leaf transpiration and stem sap flow

In the studied semi-arid forest ecosystem, leaf transpiration and xylem sap flow are never quantitatively synchronized (Fig. 5C), and even at the time of peak activity, when sap fluxes surpassed $5 \mathrm{~kg} \mathrm{hr}^{-1}$ (April) there was still a 30 min lag of $S F$ peak behind that for $T$ (Tab. 1). Such short lags are expected due to changes in tree capacitance or water content as $\Psi_{1}$ decreases during the morning (Fig. 4). The interaction of leaf conductance with water potential can involve long response times, sometimes producing sustained stomatal cycling with an average period of approximately $70 \mathrm{~min}$ (Dzikiti et al. 2007). In our study, diurnal peaks of $T$ and $S F$ (the latter peak was not as distinctive) were $9.5 \mathrm{hr}$ apart, compared to $0.5-3 \mathrm{hr}$ reported in other studies (Zweifel et al. 2001, Meinzer et al. 2003, Fisher et al. 2007). These are exceptionally long delays, which might be expected in this case of extreme drought. The lag time was inversely related to the water flux, peaking at $9.5 \mathrm{hr}$ in the height of the dry season (July - Tab. 1), when peak sap fluxes never exceeded $1 \mathrm{~kg} \mathrm{hr}^{-1}$. This could be partly explained by a higher contribution of a few sinker roots to the tree water use in the dry season, thereby reducing the overall flow and increasing the mean water path length. The inverse relationship noted above is in agreement with measurements in young spruce (Zweifel et al. 2001), where the lag increased from 30 min on high-flux days to 110 min on low-flux days. Brodersen et al. (2010) showed in grapevine that delays are related to water deficits, where cavitated vessels could not refill until addi- 
Fig. 5 - Diurnal changes in net assimilation $(A)$, photosynthetically active radiation (PAR), stomatal conductance $\left(g_{\mathrm{s}}\right)$, vapor pressure deficit $(V P D)$, leaf transpiration $(T)$, sap flow $(S F)$, stem diameter variation, and percent loss of hydraulic conductivity $(P L C)$ in Pinus halepensis during wet season (A-D) and dry season $(E-H)$ days in the Yatir forest. Note different scales for the same parameters in wet and dry seasons. Dry season curves were measured on 6 Jun 2012; wet season curves on 9 Feb 2011, except for $A, g_{\mathrm{s}}, T$ (mean curves for Jan-Feb) and PLC (9 Jan 2011). Error bars represent the standard error of the mean ( $n=1-4$, depending on the parameter), and are not observed when smaller than symbols. The dashed vertical lines in the right-hand panels denote the times 6:30, 9:30, and 11:30 discussed below.
Wet season (9 Feb 2011)
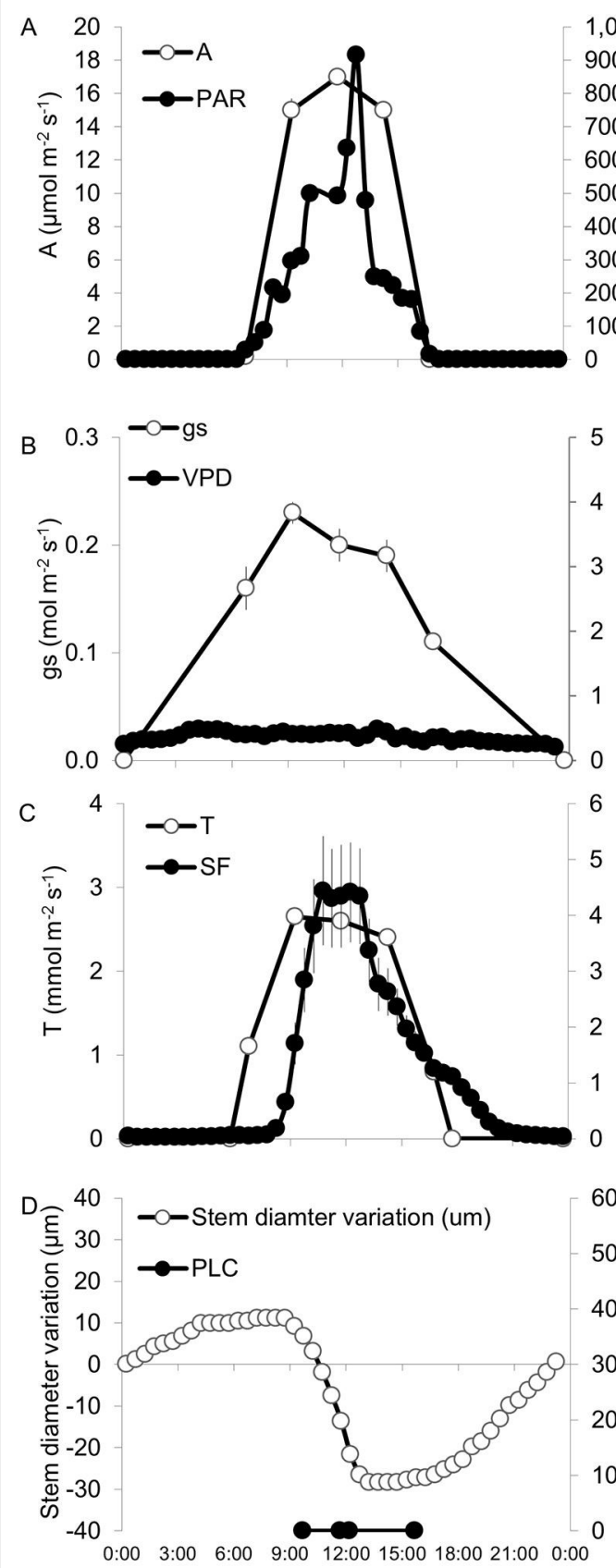

Time (hr:min)
Dry season (6 Jun 2011)

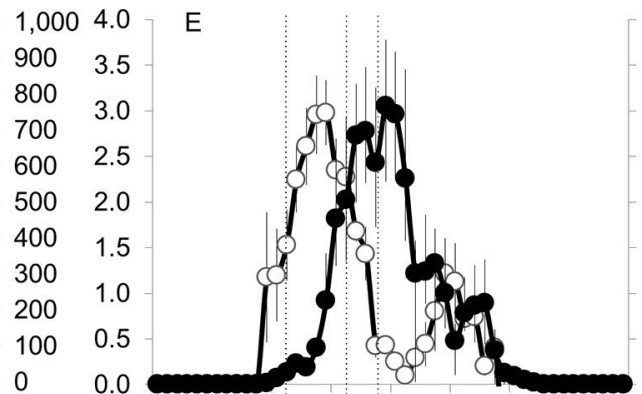

1,600

1,400

1,200 is

$1,000 \stackrel{\text { ㄹ. }}{\mathrm{N}}$

800

600

$400 \frac{\pi}{1}$

200

0.0

0

$\begin{array}{ll:l:}5 & 0.067 \mathrm{~F} & -5\end{array}$

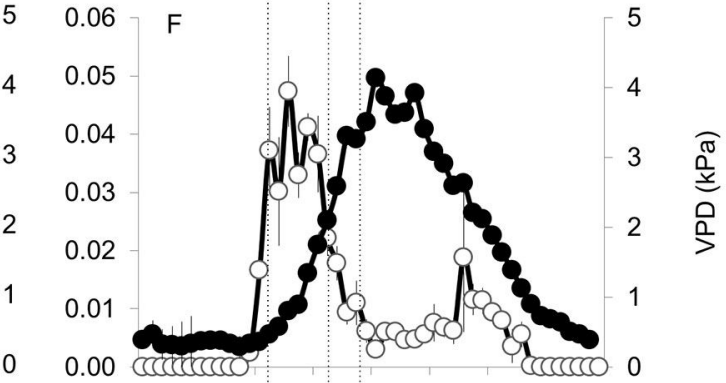

2.5

2.0

0.8

G

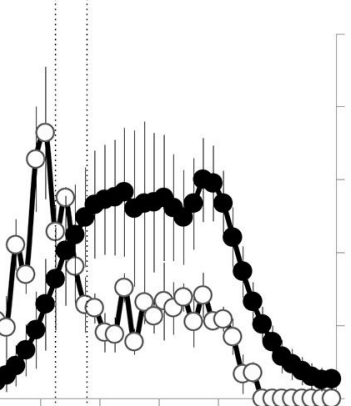

1.5

$15 \frac{2}{8}$

0.2

0

0.0

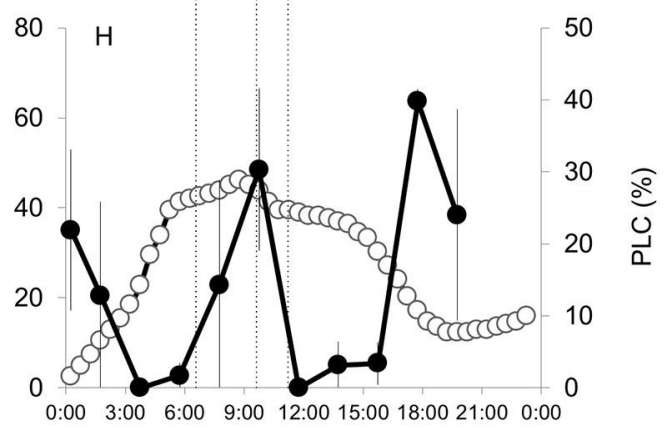

Time (hr:min) tional water was introduced. Here we show that $S F$ was often delayed into the night (Fig. 2), and consequently up to $70 \%$ of the total diurnal $S F$ occurred after sunset. This high nocturnal $S F$ proportion, which occurs when nighttime leaf transpiration is negligible, is much larger than the values of up to $35 \%$ observed in a California oak species, Quercus douglasii (Fisher et al. 2007), and up to $25 \%$ in other trees.

The calculated water storage capacity, contributing $20-33 \%$ of daily $T$, is within the range of 10-75\% reported for potted, young Norway spruce (Zweifel et al. 2001), but much higher than the $2-10 \%$ reported for yellow poplar (McLaughlin et al. 2003). This also agrees with the hypothesis that isohy- dric-like, low wood density species like $P$. halepensis should have relatively high capacity to store water (Meinzer et al. 2009). This reliance on daily water storage is equivalent to other forms of water redistribution, such as hydraulic lift and soil water storage (Oishi et al. 2010).

\section{Dynamics of xylem hydraulic}

conductivity

We detected high loss of hydraulic conductivity, which is usually associated with cavitation (PLC of $40 \%$ ) in the xylem of $P$. halepensis under drought, which was reversed on a time scale in the order of several hours (Fig. 3). These observations were consistent across four field days along three dry seasons, and across the two measurement protocols, with minor differences due to the day in the dry season. Measured PLC levels were also in agreement with the $P$. halepensis branch vulnerability curve, predicting $33 \%$ embolism at $\Psi_{1}=-3.15 \mathrm{MPa}$ (Fig. S2 in the Supplementary material). Measurements in grapevine stems revealed a diurnal cycle of cavitation and recovery, with a 3-5-hr refilling time (Brodersen et al. 2010, Zufferey et al. 2011, respectively). Shorter refilling times ( $2 \mathrm{hr}$ ) were reported for poplar (Populus trichocarpa) stems under induced embolism in the lab (Secchi \& Zwieniecki 2011). However, we noticed that some of the measurements involving the cutting of 
xylem under tension might have overestimated the levels of embolism and recovery (Wheeler et al. 2013) and hence must be taken with caution. However, our observations of two consecutive sub-diurnal cycles in PLC may be, to the best of our knowledge, the most dynamic cavitation/ recovery cycle reported for trees in the field.

Although embolism repair has been reported in conifers (Borghetti et al. 1998, McCulloh et al. 2011) and in P. halepensis specifically (Borghetti et al. 1991), its mechanism is yet to be resolved. If ray parenchyma cells and non-structural carbohydrates (NSCs) are involved, as suggested by Brodersen \& McElrone (2013), P. halepensis has both components at notable levels (Esteban et al. 2010, Klein et al. 2014a, respectively). Live parenchyma cells are also expected in the young branches studied here ( $13 \pm 1$ years, see Methods). The kinetics of xylem refilling depends on the volume of the embolized lumen, and hence on species-specific traits like conduit diameter (Brodersen et al. 2010). With its narrow tracheids $(9.4 \mu \mathrm{m}$ - Oliveras et al. 2003), P. halepensis makes a good candidate for rapid refilling. Frequent cavitation and recovery cycles can induce "cavitation fatigue", decreasing the ability of the $x y$ lem to recover (Hacke et al. 2001). However, Taneda \& Sperry (2008) reported repeated overnight xylem refilling throughout most of the summer in an oak species, similar to our observations.

Interestingly the cavitation dynamics did not always correlate with the level of water potential $\left(\Psi_{1}\right)$ in the studied branches (Fig. 4), although in situ measurements were in line with the vulnerability curve (Fig. S2 in the Supplementary material). Cavitation occurred at decreasing $\Psi_{1}$ but its reversal was not followed by increased $\Psi_{1}$ as might have been expected. Hölttä et al. (2009) proposed that $\Psi_{1}$ might increase during cavitation due to a capacitive effect. It is possible that such an effect, together with a $0.5-1.5$ hr delay, was masked by cavitation reversal.

Tab. 2 - Summary of changes in vapor pressure deficit ( $V P D)$, leaf water potential $\left(\Psi_{1}\right)$, soil water potential $\left(\Psi_{\mathrm{s}}\right)$, stomatal conductance $\left(g_{\mathrm{s}}\right)$, hydraulic conductivity $(K)$, percent loss of conductivity ( $P L C$ ), leaf transpiration ( $T$ ), and sap flow $(S F)$ in Pinus halepensis in the Yatir forest. Observed $T$ and $S F$ rates are compared with values calculated using eqn. 3 and eqn. 4, respectively.

\begin{tabular}{llcccc}
\hline \multirow{2}{*}{ Values } & Parameters & Wet season & \multicolumn{3}{l}{ Dry season } \\
\cline { 2 - 5 } & & $\mathbf{1 1 : 3 0}$ & $\mathbf{6 : 3 0}$ & $\mathbf{9 : 3 0}$ & $\mathbf{1 1 : 3 0}$ \\
\hline Observed & $V P D(\mathrm{kPa})$ & 1.5 & 0.4 & 1.9 & 3.4 \\
& $\Psi_{1}(\mathrm{MPa})$ & -1.5 & -1.5 & -3.0 & -3.0 \\
& $\Psi_{\mathrm{s}}(\mathrm{MPa})$ & -0.1 & -0.9 & -0.9 & -0.9 \\
& $g_{\mathrm{s}}\left(\mathrm{mol} \mathrm{m}^{-2} \mathrm{~s}^{-1}\right)$ & 0.18 & 0.030 & 0.030 & 0.007 \\
& $K\left(\mathrm{~kg} \mathrm{hr}^{-1} \mathrm{MPa}^{-1}\right)$ & 3.00 & 0.50 & 0.35 & 0.55 \\
& $P L C(\%)$ & 0 & 7 & 30 & 0 \\
& $T\left(\mathrm{mmol} \mathrm{m}^{-2} \mathrm{~s}^{-1}\right)$ & 3.15 & 0.13 & 0.58 & 0.25 \\
& $S F\left(\mathrm{~kg} \mathrm{hr}^{-1}\right)$ & 4.50 & 0.10 & 0.73 & 1.30 \\
Calculated & $T=g_{\mathrm{s}} \times V P D\left(\mathrm{mmol} \mathrm{m}^{-2} \mathrm{~s}^{-1}\right)$ & 2.70 & 0.12 & 0.57 & 0.24 \\
& $S F=K \times \Delta \Psi_{\mathrm{s}-1}\left(\mathrm{~kg} \mathrm{hr}^{-1}\right)$ & 4.20 & 0.30 & 0.73 & 1.16 \\
\hline
\end{tabular}

lem (30\% - Tab. 2) decreases overall $K$ from 0.50 to $0.35 \mathrm{~kg} \mathrm{hr}^{-1} \mathrm{MPa}^{-1}$ (Tab. 2). This further decouples $S F$ from $T$, increases the water deficit $\left(\sim 3 \mathrm{~kg}\right.$ tree $^{-1}$ by $\left.9: 30\right)$ and decreases $n R W C$ (from $77 \%$ to $63 \%$ in our case). Only then, stomatal closure follows, reducing $g_{\mathrm{s}}$ from $0.030 \mathrm{~mol} \mathrm{~m}^{-2} \mathrm{~s}^{-1}$ at 9:30 to $0.007 \mathrm{~mol} \mathrm{~m}^{-2} \mathrm{~s}^{-1}$ at 11:30 (Tab. 2). This overcompensates for the VPD increase (from 1.9 to $3.4 \mathrm{kPa}$ ), and hence $T$ decreases from $0.58 \mathrm{mmol} \mathrm{m}^{-2} \mathrm{~s}^{-1}$ at 9:30 to $0.25 \mathrm{mmol} \mathrm{m}^{-2} \mathrm{~s}^{-1}$ at 11:30 (eqn. 3) and $n R W C$ increases. The parallel decrease in $T$, increase in $S F$, and recovery in hydraulic conductance by 11:30 permit the closure of the hydraulic deficit that developed earlier.

Oscillations in $g_{s}$ in water-stressed woody plants have been long related to the feedback loop between $T$ and $g_{s}$ spanning over 2-4 $\mathrm{hr}$ in orange trees (Cohen \& Cohen 1983). High $V P D$ may be one of the signals that lead to stomatal closure (Oren et al. 1999), thereby facilitating recovery from cavitation. The decrease in $g_{s}$ in mid-morning and its subsequent increase in the afternoon seem to correspond to similar trends in $V P D$ and inverse trends in water deficit. The time course of change in $g_{s}$, in turn, may influence that of the cavitation/ recovery cycles. For example, in May maximum daily $V P D$ in the Yatir forest is usually below $3.0 \mathrm{kPa}$ (Maseyk et al. 2008) and hence the midday depression in $g_{\mathrm{s}}$ is restricted to 10:30-13:30, compared to 10:0016:00 in June (Fig. $5 \mathrm{~F}$ ). This can explain the shorter cavitation/recovery cycles observed in May (Fig. 3) than in June. The lower vapor pressure deficit (VPD) in September vs. May meant that stomatal gas exchange was maintained throughout the afternoon hours, which can explain the lack of hydraulic recovery during the day in our September field day (Fig. 3 and Fig. 4). Causality is of course difficult to infer from these patterns. While some studies claim that stomatal activity protects the xylem (Cruiziat et al. 2002, Yang et al. 2012), others propose that the xylem imposes a limit on $g_{s}$ and water loss (Brodribb \& Cochard 2009, Zufferey et al. 2011). Nardini \& Salleo (2000) concluded that in very dry conditions some cavitation could not be avoided, because it acts as a signal regulating $g_{s}$. This is consistent with the observation that stomatal responses both at 9:15 and 17:15 (Fig. 5F) coincided with a $P L C$ (cavitation level) of $\sim 30 \%$ (Fig. 3) and indicates a possible threshold for stomatal response, with the value for initiation of closure corresponding to a water deficit of $\sim 2.5 \mathrm{~kg}$ tree $^{-1}$. Based on these observations, we speculate that while there are complex feedbacks between $g_{s}$ and $P L C$, actual changes in leaf conductance do not correlate with threshold or cumulative changes in $P L C$, such that moderate levels of cavitation and recovery of xylem in our extremely dry conditions can be routine during daytime, thus permitting or maximizing leaf gas exchange. 
Interactions between hydraulic and physiological adjustments

The pine trees in the semi-arid study site have relatively high productivity and a range of adjustments to the dry conditions. Furthermore, these trees maintain photosynthetic activity throughout the long annual dry season, sufficiently to support the growth of new needles during this period (Maseyk et al. 2008). At the same time xylem resistance to embolism is not high in P. halepensis ( $\left.\Psi_{\mathrm{PLC} C 50}>-4.0 \mathrm{MPa}\right)$ similarly to other pine species (Brodribb et al. 2014).

Based on the results reported above we speculate that the observed temporal decoupling between water loss from the leaves and water recharge from the soil (Fig. 5G) helps to optimize the trees' water and gas exchange economy, facilitating their survival in the semi-arid conditions. Such a system operates with a relatively narrow safety margin, at the cost of significant loss in hydraulic conductivity, relying, in turn, on rapid recovery (Fig. 3). The results seem to indicate that high vulnerability to cavitation does not necessarily reflect low levels of resistance to drought, but may be part of the overall optimization between reduced water availability and the requirement for maintaining gas exchange under dry conditions. Equally important, the redistribution of water at both soil and tree levels is an essential component.

Further research is needed to focus on the different aspects of the cavitation/recovery cycle process. In addition, better tools are needed to measure cavitation in the field, facilitating more frequent sampling, which could give insight into the different environmental and physiological factors involved in forest sustainability under increasingly dry conditions in the Mediterranean and other regions.

\section{List of Abbreviations}

- $A$ : net carbon assimilation;

- $g_{\text {s: }}$ stomatal conductance;

- $K$ : hydraulic conductivity;

- $n R W C$ : needle relative water content;

- PAR: photosynthetic active radiation;

- PLC: percent loss of conductivity;

- $S F$ : sap flow;

- $T$ : transpiration;

- VPD: vapor pressure deficit.

\section{Acknowledgments}

Measurements were performed jointly by all authors. TK conceived the study and wrote the first draft of the manuscript, with all authors contributing to the writing.

TK acknowledges the Karshon foundation grant provided through KKL-JNF and the Rieger foundation grant. TK thanks Dr. Jiri Kucera of EMS Ltd., Czech Republic, and Prof. Katarina Strelcova of Zvolen Technical University, Slovakia, for training with the sap flow measurement system; and Tal Kanety of ARO Volcani, Israel, for assistance in sap flow sensor manufacturing. We thank Prof. Harvey Scher of the Weiz- mann Institute of Science for helpful discussions.

\section{Funding}

This work was supported by KKL-JNF and the Israel ministry of Agriculture; the Sussman Center and the Cathy Wills and Robert Lewis Program in Environmental Science of the Weizmann Institute; the Israel ministry of Science (France-Israel High Council for Research Scientific and Technological Cooperation, project 3-6735); the Minerva Foundation, The Israeli Science Foundation (ISF), and the COST FORMAN (Forest Management and the Water Cycle, FP0601) program.

The authors declare no conflict of interest.

\section{Data Accessibility}

All data are included in the manuscript and supporting information.

\section{References}

Borghetti M, Edwards WRN, Grace J, Jarvis PG, Raschi A (1991). The refilling of embolized $x y-$ lem in Pinus sylvestris L. Plant, Cell and Environment 14: 357-369. - doi: 10.1111/j.1365-3040.1991. tboog44.x

Borghetti M, Cinnirella S, Magnani F, Saracino A (1998). Impact of long-term drought on xylem embolism and growth in Pinus halepensis Mill. Trees 12: 187-195. - doi: 10.1007/PLo0009709

Brodersen CR, McElrone AJ (2013). Maintenance of xylem network transport capacity: a review of embolism repair in vascular plants. Frontiers in Plant Science 4: 1-11. - doi: 10.3389/fpls.2013. 00108

Brodersen CR, McElrone AJ, Choat B, Matthews MA, Shackel KA (2010). The dynamics of embolism repair in xylem: in vivo visualizations using high-resolution computed tomography. Plant Physiology 154: 1088-1095. - doi: 10.1104/ pp.110.162396

Brodribb TJ, Cochard H (2009). Hydraulic failure defines the recovery and point of death in water-stressed conifers. Plant Physiology 149: 575-84. - doi: 10.1104/pp.108.129783

Brodribb TJ, McAdam SA, Jordan GJ, Martins SC (2014). Conifer species adapt to low-rainfall climates by following one of two divergent pathways. Proceedings of the National Academy of Sciences USA 111: 14489-14493. - doi: 10.1073/ pnas.1407930111

Choat B, Jansen S, Brodribb TJ, Cochard H, Delzon S, Bhaskar R, Bucci SJ, Feild TS, Gleason SM, Hacke UG, Jacobsen AL, Lens F, Maherali H, Martínez-Vilalta J, Mayr S, Mencuccini M, Mitchell PJ, Nardini A, Pittermann J, Pratt RB, Sperry JS, Westoby M, Wright IJ, Zanne AE (2012). Global convergence in the vulnerability of forests to drought. Nature 491: 752-755. doi: $10.1038 /$ nature 11688

Choat B, Brodersen CR, McElrone AJ (2014). Synchrotron X-ray microtomography of xylem embolism in Sequoia sempervirens saplings during cycles of drought and recovery. New Phytologist. - doi: 10.1111/nph.13110

Cohen S, Cohen Y (1983). Field studies of leaf conductance response to environmental variables in citrus. Journal of Applied Ecology 20:
561-570. - doi: 10.2307/2403526

Cohen Y, Cohen S, Cantuarias-Aviles T, Schiller G (2008). Variations in the radial gradient of sap velocity in trunks of forest and fruit trees. Plant and Soil 305: 49-59. - doi: 10.1007/s11104-0079351-0

Cruiziat P, Cochard H, Ameglio T (2002). Hydraulic architecture of trees: main concepts and results. Annals of Forest Science 59: 723752. - doi: 10.1051/forest:2002060

Delzon S, Douthe C, Sala A, Cochard H (2010). Mechanism of water-stress induced cavitation in conifers: bordered pit structure and function support the hypothesis of seal capillary-seeding. Plant, Cell and Environment 33: 2101-2111. doi: 10.1111/j.1365-3040.2010.02208.x

Dzikiti S, Steppe K, Lemeur R, Milford JR (2007). Whole-tree level water balance and its implications on stomatal oscillations in orange trees (Citrus sinensis L. Osbeck) under natural climatic conditions. Journal of Experimental Botany 58: 1893-1901. - doi: 10.1093/jxb/ermo23

Espino S, Schenk HJ (2011). Mind the bubbles: achieving stable measurements of maximum hydraulic conductivity through woody plant samples. Journal of Experimental Botany 62: 1119-32. - doi: 10.1093/jxb/erq338

Esteban LG, Martin JA, De Palacios P, Fernandez FG, Lopez R (2010). Adaptive anatomy of Pinus halepensis trees from different Mediterranean environments in Spain. Trees 24: 19-30. - doi: 10.1007/s00468-009-0375-3

Fisher JB, Baldocchi DD, Misson L, Dawson TE, Goldstein AH (2007). What the towers don't see at night: nocturnal sap flow in trees and shrubs at two AmeriFlux sites in California. Tree Physiology 27: 597-610. - doi: 10.1093/treephys/ 27.4.597

Granier A, Loustau D (1994). Measuring and modeling the transpiration of a maritime pine canopy from sap-flow data. Agricultural and Forest Meteorology 71: 61-81. - doi: 10.1016/ 0168-1923(94)90100-7

Grünzweig JM, Gelfand I, Yakir D (2007). Biogeochemical factors contributing to enhanced carbon storage following afforestation of a semiarid shrubland. Biogeosciences 4: 891-904. doi: 10.5194/bg-4-891-2007

Hacke UG, Stiller V, Sperry JS, Pittermann J, McCulloh KA (2001). Cavitation fatigue. Embolism and refilling cycles can weaken cavitation resistance of xylem. Plant Physiology 125: 779-786. - doi: 10.1104/pp.125.2.779

Holbrook NM, Zwieniecki MA (1999). Embolism repair and xylem tension: do we need a miracle? Plant Physiology 120: 7-10. - doi: 10.1104/pp. 120.1.7

Hölttä T, Nikinmaa E, Mencuccini M (2009). Linking phloem function to structure: analysis with a coupled xylem-phloem transport model. Journal of Theoretical Biology 259: 325-337. - doi: 10.1016/j.jtbi.2009.03.039

Kanety T, Naor A, Gips A, Dicken U, Lemcoff JH, Cohen $S$ (2014). Irrigation influences on growth, yield, and water use of persimmon trees. Irrigation Science 32: 1-3. - doi: 10.1007/ s00271-013-0408-y

Klein T, Cohen S, Yakir D (2011). Hydraulic adjustments underlying drought resistance of Pinus halepensis. Tree Physiology 31: 637-648. - doi: 10.1093/treephys/tpro47 
Klein T, Di Matteo G, Rotenberg E, Cohen S, Yakir $D$ (2012). Differential ecophysiological response of a major Mediterranean pine species across a climatic gradient. Tree Physiology 33: 26-36. doi: $10.1093 /$ treephys/tps116

Klein T, Hoch G, Körner C, Yakir D (2014a). Drought stress, growth, and nonstructural carbohydrate dynamics of pine trees in a semi-arid forest. Tree Physiology 34: 981-992. - doi: 10.1093/treephys/tpu071

Klein T, Rotenberg E, Cohen-Hilaleh E, Raz-Yaseef N, Tatarinov F, Ogée J, Cohen S, Yakir D (2014b). Quantifying transpirable soil water and its relations to tree water use dynamics in a water-limited pine forest. Ecohydrology 7: 409419. - doi: $10.1002 /$ eco.1360

Maseyk KS, Lin T, Rotenberg E, Grünzweig JM, Schwartz A, Yakir D (2008). Physiology-phenology interactions in a productive semi-arid pine forest. New Phytologist 178: 603-16. - doi: 10.1111/j.1469-8137.2008.02391.x

McCulloh K, Johnson DM, Meinzer FC, Lachenbruch B (2011). An annual pattern of native embolism in upper branches of four tall conifer species. American Journal of Botany 98: 10071015. - doi: 10.3732/ajb.1000503

McLaughlin SB, Wullschleger SD, Nosal M (2003). Diurnal and seasonal changes in stem increment and water use by yellow poplar trees in response to environmental stress. Tree Physiology 23: 1125-36. - doi: 10.1093/treephys/ 23.16.1125

Meinzer FC, McCulloh KA (2013). Xylem recovery from drought-induced embolism: where is the hydraulic point of no return? Tree physiology 33: 331-334. - doi: 10.1093/treephys/tpt022

Meinzer FC, James SA, Goldstein G, Woodruff D (2003). Whole-tree transport scales with sapwood capacitance in tropical forest canopy trees. Plant, Cell and Environment 26: 1147-55. doi: 10.1046/j.1365-3040.2003.01039.x

Meinzer FC, Johnson DM, Lachenbruch B, McCulloh KA, Woodruff DR (2009). Xylem hydraulic safety margins in woody plants: coordination of stomatal control of xylem tension with hydraulic capacitance. Functional Ecology 23: 922-930. - doi: 10.1111/j.1365-2435.2009.01577.x Melcher PJ, Holbrook NM, Burns MJ, Zwieniecki MA, Cobb AR, Brodribb TJ, Choat B, Sack L (2012). Measurements of stem xylem hydraulic conductivity in the laboratory and field. Methods in Ecology and Evolution 3: 685-694. - doi: 10.1111/j.2041-210X.2012.00204.x

Nardini A, Salleo S (2000). Limitation of stomatal conductance by hydraulic traits: sensing or preventing xylem cavitation? Trees 15: 14-24. - doi: 10.1007/s004680000071

Ogasa M, Miki NH, Murakami Y, Yoshikawa K (2013). Recovery performance in xylem hydraulic conductivity is correlated with cavitation resistance for temperate deciduous tree species. Tree Physiology 33: 335-344. - doi: 10.1093/treephys/tpt010

Oishi AC, Oren R, Novick KA, Palmroth S, Katul GG (2010). Interannual invariability of forest evapotranspiration and its consequence to water flow downstream. Ecosystems 13: 421436. - doi: 10.1007/s10021-010-9328-3

Oliveras IJ, Martínez-Vilalta J, Jimenez-Ortiz MJ, Lledó A, Escarré A, Piñol J (2003). Hydraulic properties of Pinus halepensis, Pinus pinea and Tetraclinis articulata in a dune ecosystem of Eastern Spain. Plant Ecology 169: 131-41. - doi: 10.1023/A:1026223516580

Oren R, Sperry JS, Katul GG, Pataki DE, Ewers BE, Phillips N, Schaefer KVR (1999). Survey and synthesis of intra- and interspecific variation in stomatal sensitivity to vapour pressure deficit. Plant, Cell and Environment 22: 1515-1526. - doi: 10.1046/j.1365-3040.1999.00513.x

Paudel I, Kanety T, Cohen S (2013). Inactive xylem can explain differences in calibration factors for thermal dissipation probe sap flow measurements. Tree Physiology 33: 986-1001. doi: $10.1093 /$ treephys/tpto70

Secchi F, Zwieniecki MA (2011). sensing embolism in xylem vessels: the role of sucrose as a trigger for refilling. Plant, Cell and Environment 34: 514-524. - doi: 10.1111/j.1365-3040.2010.0225 9.x

Steppe K, De Pauw DJW, Doody TM, Teskey RO (2010). A comparison of sap flux density using thermal dissipation, heat pulse velocity and heat field deformation methods. Agricultural and Forest Meteorology 150: 1046-56. - doi: 10.1016/j.agrformet.2010.04.004

Taneda H, Sperry JS (2008). A case-study of water transport in co-occurring ring- versus diffuse-porous trees: contrasts in water status, conducting capacity, cavitation and vessel refilling. Tree Physiology 28: 1641-1651. - doi: 10.1093/ treephys/28.11.1641

Trifilò P, Barbera PM, Raimondo F, Nardini A, Lo Gullo MA (2014). Coping with drought-induced xylem cavitation: coordination of embolism repair and ionic effects in three Mediterranean evergreens. Tree Physiology 34: 109-122. - doi: 10.1093/treephys/tpt119
Tyree MT, Alexander JD (1993). Hydraulic conductivity of branch junctions in three temperate tree species. Trees 7: 156-9. - doi: 10.1007/BF 00199616

Tyree MT, Sperry JS (1988). Do woody plants operate near the point of catastrophic xylem dysfunction caused by dynamic water stress? Answers from a model. Plant Physiology 88: 574-580. - doi: 10.1104/pp.88.3.574

Tyree MT, Salleo S, Nardini A, Lo Gullo MA, Mosca R (1999). Refilling of embolized vessels in young stems of Laurel. Do we need a new paradigm? Plant Physiology 120: 11-21. - doi: 10.1104/pp.120.1.11

Waring RH, Silvester WB (1994). Variation in foliar $\delta^{13} \mathrm{C}$ values within the crowns of Pinus radiata trees. Tree physiology 14: 1203-13. - doi: 10.1093/treephys/14.11.1203

Wheeler JK, Huggett BA, Tofte AN, Rockwell FE, Holbrook NM (2013). Cutting xylem under tension or supersaturated with gas can generate PLC and the appearance of rapid recovery from embolism. Plant, Cell and Environment 36: 1938-1949. - doi: 10.1111/pce.12139

Yang S-J, Zhang Y-J, Sun M, Goldstein G, Cao K-F (2012). Recovery of diurnal depression of leaf hydraulic conductance in a subtropical woody bamboo species: embolism refilling by nocturnal root pressure. Tree Physiology 32 (4): 414422. - doi: 10.1093/treephys/tpso28

Zufferey V, Cochard H, Ameglio T, Spring J-L, Viret $O$ (2011). Diurnal cycles of embolism formation and repair in petioles of grapevine (Vitis vinifera cv. Chasselas). Journal of Experimental Botany 62: 3885-3894. - doi: 10.1093/jxb/erro81 Zweifel R, Item H, Haesler R (2001). Link between diurnal stem radius and tree water relations. Tree Physiology 21: 869-877. - doi: 10.1093 /treephys/21.12-13.869

\section{Supplementary Material}

Fig. S1 - The effect of hydrostatic pressure on specific hydraulic conductivity $\left(K_{\mathrm{s}}\right)$ of Pinus halepensis branches.

Fig. S2 - Xylem vulnerability curve for Pinus halepensis branches: percent loss of hydraulic conductivity (PLC) as function of branch water potential (WP).

Link: Klein_2046@supploo1.pdf 